\title{
The Systematic Application of Network Diagnostics to Monitor and Tackle Bullying and Victimization in Schools
}

\author{
Tessa M. L. Kaufman ${ }^{1}$ (D) Gijs Huitsing ${ }^{1}$ (D) $\cdot$ Rick Bloemberg $^{1} \cdot$ René Veenstra $^{1}$ (D) \\ Published online: 15 February 2020 \\ (C) The Author(s) 2020
}

\begin{abstract}
Despite increased attention to tackling bullying and the use of effective anti-bullying programs that can reduce victimization for many, some children remain victimized. Preventing persistent victimization requires that teachers identify victims and intervene at an early stage, but this is often difficult because teachers cannot always recognize victimization or the underlying social dynamics that determine what kind of interventions are necessary. This proposal discusses how network diagnostics of the social structure of the classroom can help teachers to recognize and reduce victimization more systematically. First, it discusses research that shows promising effects of the use of network diagnostics to reduce health problems. It describes how these diagnostics (for bullying and victimization, social position, and school well-being) can help in recognizing victimization and tailoring interventions to the most relevant students. Second, this proposal discusses a systematic stepwise approach for teachers to interpret the diagnostics and translate them into structural actions. Overall, this proposal aims to raise awareness of the potential of network information to facilitate the daily practice of reducing bullying and gives researchers directions for further empirical research on teachers' role in tackling bullying and on the situations that may affect whether their approaches are effective. Moreover, it discusses potential barriers to teachers' use of network diagnostics, such as a lack of time and resources at school.
\end{abstract}

Keywords Victimization $\cdot$ Social network diagnostics $\cdot$ Teachers $\cdot$ Systematic prevention

Bullying is repeated, goal-directed behavior that harms another individual in the context of a power imbalance (Olweus 1993). In recent decades, there has been a worldwide increase in societal and political attention to bullying, resulting in anti-bullying laws (Cornell and Limber 2015; UNESCO 2017) and antibullying programs that are carried out in the school context (see for overviews Gaffney et al. 2019; Yeager et al. 2015).

Teachers play an important role in these programs, because their actions can contribute to reducing bullying (Fekkes et al.

Tessa M. L. Kaufman

t.m.1.kaufman@rug.nl

Gijs Huitsing

g.e.huitsing@rug.nl

Rick Bloemberg

r.bloemberg@ rug.nl

René Veenstra

d.r.veenstra@rug.nl

1 Department of Sociology \& ICS, University of Groningen, Groningen, Netherlands
2005; Garandeau et al. 2014b; Haataja et al. 2014). Moreover, they frequently interact with other potentially involved parties, such as the peer group, school staff, and parents. Even the most effective interventions can only reduce victimization by up to $20 \%$ (Gaffney et al. 2019). Students who are not helped by these interventions often remain victimized for 2 years or longer, because their problems are unnoticed or unaddressed (Brendgen and Poulin 2018; Kaufman et al. 2018). Broader prevention may help to further reduce bullying but may not help teachers to recognize or respond to more complex situations, including persistent victimization. Therefore, in addition to a universal component for all students, school-based anti-bullying interventions need tailored approaches for students who are not helped by the universal components (Farmer et al. 2007). However, many teachers struggle to recognize all (persistent) victims (Campbell et al. 2019; Haataja et al. 2015b; Oldenburg et al. 2016). Moreover, they do not always respond to bullying with concrete actions and do not always follow up on previous actions (Ellis and Shute 2007; Van der Ploeg et al. 2016), even if they are following an effective anti-bullying program. Thus, there is a need for tailored measures that enable teachers to improve 
their recognition of and actions for persistent victims who are not helped by effective school-based interventions.

We propose reasons why, and how, primary school professionals' recognition of victimization, and their tailored responses to it can be improved through the systematic use of network diagnostics (Gest et al. 2011). These are easily interpretable diagnostics of the social structure of the relationships in classrooms, often based on students' answers to a questionnaire. These diagnostics can be used not only to recognize victims or at-risk students but also to design interventions to target relevant students in the peer group (Valente 2012). Therefore, interventions are tailored to the particular situation (Cunningham et al. 2019; Saarento et al. 2015). Multiple studies have shown that network diagnostics can be used effectively in practice to reduce other health problems (for an overview, see Valente and Pitts 2017). Moreover, research has demonstrated that relationship information can be valuable to explain bullying processes (e.g., Sainio et al. 2011; Van Der Ploeg et al. 2020). This information can also be used in daily practice to reduce bullying.

However, monitoring bullying and related social dynamics may only be effective when teachers receive the most theoretically relevant information and when they are guided in systematically handling the abstract information (De Shazer and Dolan 2007; Deming 1989; Kok et al. 2016). This proposal, therefore, provides a theoretical analysis of the potential of network diagnostics to enable teachers to recognize and reduce victimization more systematically. It also encourages empirical analysis of their effects.

\section{Network Diagnostics to Recognize and Reduce Victimization}

Network diagnostics concern the use of analytics to investigate relational characteristics of behavior (who is connected to whom), such as social preferences and reputation or bullying relationships (Gest et al. 2011; Valente 2012). Network diagnostics may enable people to recognize relational problems and to reduce them using tailored interventions that target the relevant actors in the network (Gesell et al. 2013; Valente 2012). These interventions are aimed at accelerating behavior change or improving the social atmosphere in a group. Network data can be used to identify individuals or subgroups with a central role in the network (i.e., being highly connected or having high status). These people can set the norm and diffuse information or behaviors or can create cascades of behavior change in the network (Dijkstra et al. 2008). In addition, network data can be used to alter the network by rewiring existing relationships or even by adding or removing certain group members to or from the network (Valente 2012).

Empirical evidence in other domains supports the value of network diagnostics in inducing behavior change. Network processes have been found to mediate or moderate the effectiveness of a wide range of health interventions (Valente and Pitts 2017). A randomized controlled trial (RCT) showed that targeting the most influential (most popular/best leaders) peers in the classroom stimulated peer influence on children's own increased water consumption (Smit et al. 2016). Relatedly, an RCT on an intervention aimed at decreasing conflict between students showed that students who had more network connections had greater influence on social norms and behaviors in their peer network and, therefore, made the greatest contributions to a decrease in conflict (Paluck et al. 2018). Another experiment showed that network diagnostics helped in targeting only adolescents without friends who used substances for an intervention to reduce substance use (Valente et al. 2007), because the intervention was only effective for this group. Last, interventions were successful in creating new social advice and discussion networks for children (Gesell et al. 2013), and in expanding and strengthening professional networks of university teachers (Van Waes et al. 2018).

Similarly, network diagnostics can be valuable in recognizing and reducing social problems such as bullying processes. Bullying is by nature a phenomenon that occurs at the level of relationships and in which the peer group plays a central role (Salmivalli 2010). Bullies target one or more victims, but these bullies and victims are also embedded in a classroom context in which students encourage or discourage bullying processes. It is, therefore, important to understand the involvement of all group members in bullying (Rambaran et al. 2019). This relational perspective on bullying has found its way into effective group-based anti-bullying interventions aimed at changing group-level social dynamics (Evans et al. 2014). These interventions aim to influence the peer group in such a way that more students will express their disapproval of bullying and defend victims (Kärnä et al. 2011). This disapproval and support can eliminate the motivating social rewards that reinforce bullies' detrimental behavior (Juvonen and Ho 2008; Olthof et al. 2011; Pöyhönen et al. 2010; Salmivalli et al. 2011). Strategic bullies are particularly sensitive to disapproval from relevant peers such as friends, but not to rejection by victims and their defenders (Veenstra et al. 2010). Although bullying can take a number of different forms, all these forms likely result from the same fundamental goal to achieve social dominance (Sijtsema et al. 2009) and often co-occur (Antoniadou et al. 2019). Therefore, bullies' sensitivity to peers' responses and interventions that target group processes can be generalized across different manifestations of bullying, such as online and offline bullying (Williford et al. 2013).

The social dynamics involved in bullying are most easily visible in the classroom context but are sometimes difficult even for teachers to recognize (Haataja et al. 2015b; Neal et al. 2011; Oldenburg et al. 2016). However, these dynamics can be identified using network information (Wölfer and 
Scheithauer 2014). This can enable teachers to recognize problems in the network and target the most influential peers for interventions.

It is important to raise awareness of the potential value of the systematic use of network information to facilitate the daily practice of tackling bullying. With this in mind, we propose a conceptual model for how to utilize network diagnostics. We describe how they can be obtained and presented, and propose a stepwise approach that enables teachers to systematically interpret and apply the diagnostics and translate them into action.

\section{Methods: Collecting and Presenting Network Diagnostics}

Network diagnostics can be collected in classrooms using an online monitoring tool. This tool is based on a preferably online survey for all students in the peer group, and consists of both self-reported information and social network questions about students' relationships. In this way, information can be obtained about the relevant relationships between all children in the classroom. We propose three types of diagnostics: bullying and victimization, social position (friendships, social preference, and social reputation), and school well-being.

\section{Measures}

\section{Bullying and Victimization}

Bullying and victimization can be assessed by combining selfreported information on victimization with network information about who bullies whom (Felix et al. 2011; Furlong et al. 2010). The advantages of self-reports of victimization are that they capture specific experiences that are often unnoticed by others and that they indicate the severity of the problems because they are closely related to victims' emotional problems (Solberg and Olweus 2003).

Self-reported victimization can be assessed using the Olweus' (1996) Bully/Victim Questionnaire, which provides children with a definition of bullying. Children respond to one global item ("How often have you been bullied during the past couple of months?") followed by questions about specific forms of bullying. These items distinguish five forms of bullying (seven items in total): physical, verbal (two items), relational (two items), material (taking or breaking others' property), and cyber-victimization (receiving nasty or insulting messages, calls, or pictures). Children answer on a five-point scale how often they experienced each form: $0=$ not at all, $1=$ only once or twice, $2=$ two or three times a month, $3=$ about once a week, $4=$ several times per week. Students are considered to be victimized when they are victimized in any form at least monthly (Solberg and Olweus 2003). It can be valuable to complement this measure with self-report questions that help to distinguish victimization through bullying from victimization through other types of peer aggression. This can be done by asking victims about their experiences with the key characteristics of bullying (Kaufman, Huitsing, \& Veenstra, 2020).

Additional nominations of perceived victim-bully relationships can complement this information to improve understanding of group processes ("Who starts when you are bullied?").

\section{Friendships and Social Preferences}

Friendships and social preferences refer to the maintenance of close, affectional relationships with peers within the group (De Bruyn et al. 2009). Friendships can be assessed using the question "Who are your best friends?", and social preference is usually derived from liked most, thus acceptance, and liked least, thus rejection, nominations (Coie et al. 1982).

\section{Social Reputation}

Social reputation referring to individuals' social impact in the peer group (Cillessen and Mayeux 2004; Dijkstra et al. 2008) can be valuable to understand why the bullying persists. Social reputation measures can include the number of nominations received for prosocial behavior (e.g., "Who helps you with problems/homework), popularity ("Who is the most popular?"), and leadership ("Who is a good leader?").

\section{School Well-Being}

School well-being concerns experienced safety in the classroom and students' feelings and experiences on a typical school day. It can be assessed using a set of seven selfreported questions (Kärnä et al. 2011), with questions reflecting general liking of school (e.g., "I like it at school") and feelings of safety (e.g., "I feel safe at school" $(0=$ never, $3=$ always), $\alpha=0.85$.

\section{Translating the Monitor Information into Reports}

Social network nominations can be aggregated into a total score to determine children's relative position on that measure in the peer group (Veenstra et al. 2005). This means that for each student, nominations received (or sent, for victimization) can be summed and divided by the number of participants, resulting in proportion scores $(0-1)$. Alternatively, the diagnostics can be visualized by using sociograms or "network graphs" that show all relationships and reveal subgroups in the network (Gesell et al. 2013; Huitsing and Veenstra 2012). Self-reported information can also be included in these graphs. 
Table 1 Hypothetical diagnostics of the aggregated number of classmates who nominated a student per measure, and self-reports of victimization and school well-being

\begin{tabular}{|c|c|c|c|c|c|c|c|c|c|}
\hline \multirow{5}{*}{$\begin{array}{l}\text { Student } \\
\text { Class average }\end{array}$} & \multicolumn{7}{|c|}{ Received network nominations } & \multicolumn{2}{|l|}{ Self-report } \\
\hline & \multirow{4}{*}{$\begin{array}{l}\text { Bullying } \\
1 \\
\text { Bully } \\
0.36\end{array}$} & \multicolumn{3}{|c|}{ Social preference } & \multicolumn{3}{|c|}{ Social reputation } & \multirow{2}{*}{$\begin{array}{l}\text { Victimization } \\
8\end{array}$} & \multirow{2}{*}{$\begin{array}{l}\text { Well-being } \\
9\end{array}$} \\
\hline & & 2 & 3 & 4 & 5 & 6 & 7 & & \\
\hline & & Best friend & Liked & Disliked & Popular & Leader & Prosocial & Yes/no & Level \\
\hline & & 2.65 & 6.31 & 2.69 & 3.46 & 2.73 & 2.81 & - & - \\
\hline \multicolumn{10}{|l|}{ Girls } \\
\hline Liz & & 0 & 0 & 8 & 1 & 2 & 1 & & \\
\hline Anna & 3 & 5 & 10 & 2 & 8 & 8 & 2 & & \\
\hline Meg & & 3 & 6 & 1 & 6 & 2 & 7 & & \\
\hline Cho & & 3 & 7 & 2 & 4 & 9 & 7 & & \\
\hline Jazz & & 5 & 8 & 2 & 5 & 7 & 9 & & \\
\hline Debby & & 6 & 8 & 2 & 6 & 5 & 10 & & \\
\hline Roxanne & & 3 & 7 & 2 & 1 & 2 & 1 & & \\
\hline Sarah & & 2 & 7 & 1 & 2 & 1 & 1 & & Low \\
\hline Sophie & & 0 & 2 & 4 & 1 & 1 & 2 & Yes & Very low \\
\hline Nyen & & 1 & 6 & & & 1 & 2 & & \\
\hline Emma & & 2 & 11 & 3 & 2 & 2 & 2 & & \\
\hline Olivia & & 3 & 10 & 2 & 2 & 3 & 3 & & \\
\hline \multicolumn{10}{|l|}{ Boys } \\
\hline Jacob & & 3 & 3 & 2 & 1 & 1 & 1 & & \\
\hline Mason & & 1 & 6 & 2 & 2 & 2 & 2 & & Low \\
\hline William & & 2 & 10 & 3 & 1 & 1 & 4 & & \\
\hline Jayden & & 4 & 10 & 1 & & 9 & 3 & & \\
\hline Isaac & 2 & 3 & 3 & 9 & 7 & 2 & 2 & & \\
\hline Ethan & 2 & 3 & 3 & 11 & 8 & 2 & 1 & & Very low \\
\hline Elijah & 2 & 4 & 3 & 2 & 8 & 1 & 3 & & \\
\hline David & & 4 & 6 & & 1 & & 2 & & \\
\hline Thomas & & 2 & 7 & 2 & 2 & 1 & & & Low \\
\hline Kylo & & 2 & 6 & 2 & 2 & 2 & 2 & & \\
\hline Hakeem & & 2 & 6 & & 6 & 2 & 2 & & \\
\hline Zayn & & 2 & 6 & 3 & 7 & 2 & 3 & & \\
\hline Mikael & & 2 & 7 & 2 & 6 & 1 & 1 & & \\
\hline Zyaire & & 2 & 6 & 2 & 1 & 2 & & Yes & \\
\hline
\end{tabular}

Columns 1-7 show the numbers of classmates that name a student as a bully (column 1), a best friend (column 2), liked (column 3), disliked (column 4), popular (column 5), a leader (column 6), or prosocial (column 7). For example, Anna is named by three classmates as a bully. Columns 8-9 show worrisome levels of self-reported victimization (yes-no) and school well-being (low-very low). Numbers in italics refer to low or high scores: those who are nominated by $>2$ classmates as a bully, by $<1$ classmate as a friend, are liked by $<20 \%$ or $>35 \%$ of the classmates, and are nominated by $>20 \%$ of the classmates as rejected, most popular, a good leader, or prosocial

Table 1 and Fig. 1 provide examples of a graphical presentation of the described network diagnostics based on hypothetical data. These graphics are based on those that are provided to teachers in schools that work with the Dutch KiVa program. The individual-level Table 1 shows the average number of nominations for each measure per student in the classroom, and per student, the aggregated number of nominations received (columns 1-7), and worrisome levels of self-reported victimization frequency and school well-being (columns 8 and 9). The table emphasizes the scores of the students who stand out because of their extreme scores.

The diagnostics can also be visualized by using a network graph that displays reciprocal friendships and 


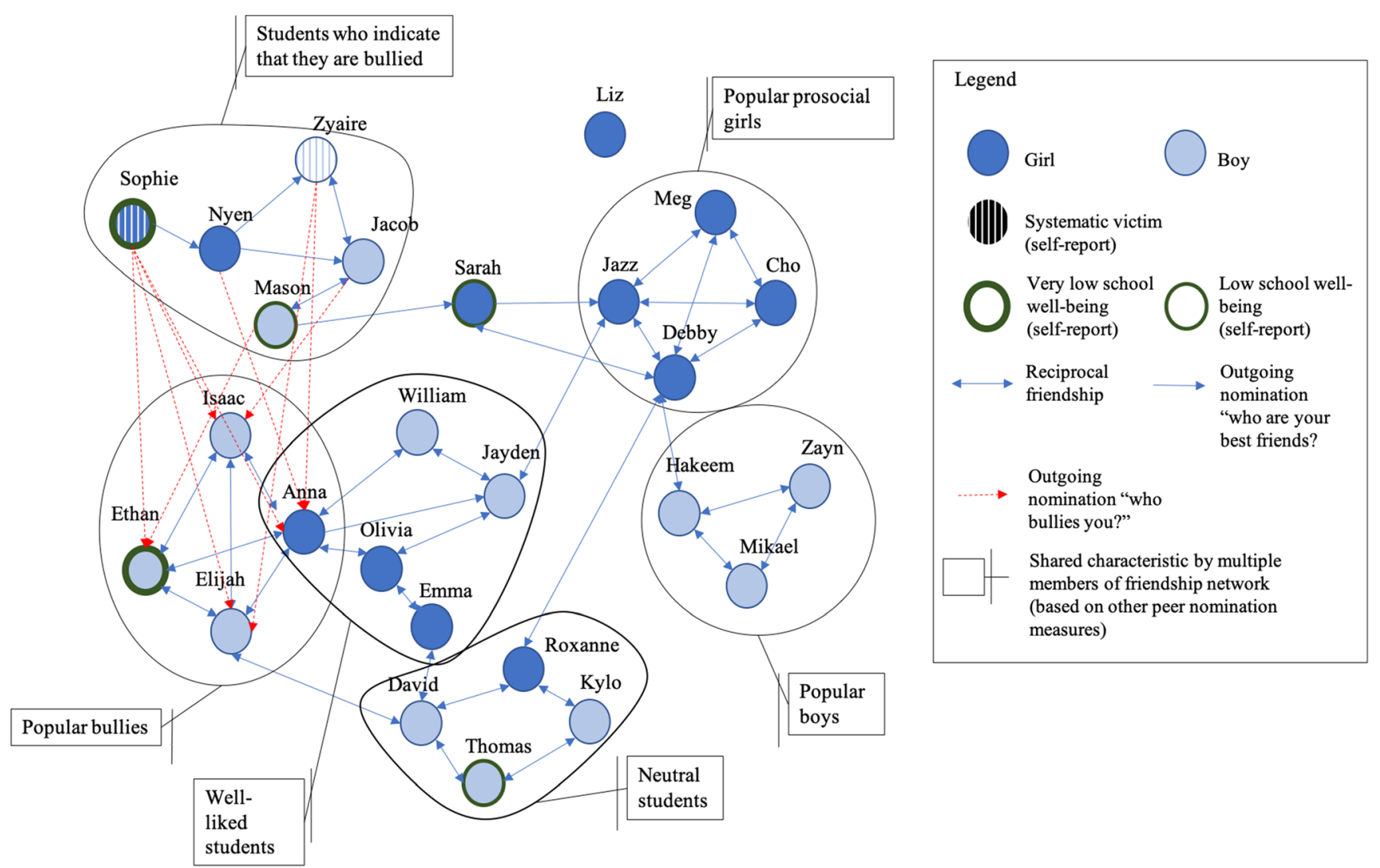

Fig. 1 Friendship network in a fictional classroom using hypothetical data

subgroups in addition to individual attributes (Fig. 1). This figure can provide insight into the relationships in the classroom and reveals subgroups of students who share certain social characteristics. Figure 1 complements Table 1 by showing not only that students are connected but also to whom. The network graph can be extended to show multiple kinds of relationships (e.g., victim-bully or victim-defender relationships) and can include individual characteristics such as school well-being.

Some schools may prefer not to disclose personal information about individual students to teachers for ethical or legal reasons, In that case, the network Fig. 1 with individual answers (bullying/friendships) can best be omitted. Table 1 provides sufficient information. This table does not show students' direct answers to the questionnaire: it only consists of aggregated information and combined information based on multiple answers to a questionnaire, which concern scales that represent the well-being scale and victimization. Schools can also choose to start with the aggregated information but may ask permission to proceed with closer examination of the problems by using a network graph only when the aggregated information indicates problems. Schools are explicitly told that the information should not be shared, for example, with students or parents.

\section{Proposed Results and Interpretation}

\section{Systematic Use of Network Diagnostics Through the Five-Step Intervention Cycle}

Optimal use of network diagnostics requires a systematic stepby-step approach that allows teachers to use the presented information. We propose an approach based on the "intervention cycle", which refers to the chronological stepwise structure of intervening (De Shazer and Dolan 2007; Deming 1989; Kok et al. 2016). The general structure of the cycle consists of five steps, starting with (1) identifying the problem, followed by (2) understanding the problem, (3) deciding on an action plan, (4) taking action, and (5) reflecting on the actions. While taking the first two steps and the last step involves mostly answering knowledge questions that require an analysis of the problem, the third and the fourth step are practical questions to find a tailored solution based on the insights gained in the previous steps (Wieringa 2009). The cycle resembles the common problem-solving process and shares aspects of the Plan-Do-Check-Act (PDCA) approach (Matsuo and Nakahara 2013; Shewhart 1939). The cycle is used by psychologists and pedagogics to handle diagnostics of other socio-emotional problems (e.g., De Shazer and Dolan 2007; Madden et al. 1992). Moreover, educational professionals are 
familiar with its use in handling students' academic problems. They often use this cycle by documenting the findings from each step: the analysis of the problem, the action plans, and reflection on the actions and adjustments. The resulting stepwise overviews of every addressed problem can help professionals to keep track of their analyses and plans during the intervention process, and can be useful in dealing with future problems of the same students or in similar situations.

Teachers could also use this intervention cycle when using network diagnostics as part of their approach to reducing victimization. They could benefit from a digitalized tool that encourages and reminds them to go through every step of the cycle explicitly and chronologically while interpreting the diagnostics. Teachers would also need to briefly report their findings in every step, resulting in brief summary overviews of the intervention cycle for every victim. Figure 2 displays our proposed design for this approach. Teachers start an intervention cycle when they receive the network diagnostics and go through the first four steps of the cycle in the weeks thereafter. They then receive new network diagnostics and reflect on the effects of their actions (step 5), after which they proceed again with step 1.

\section{Step 1: Identify}

The identify step enables teachers to see whether there are victims and report these. The network diagnostics are particularly important in this step because teachers can use them to check their own perceptions about vulnerable students and to complement their observations with students' reports.

Bullying and Victimization The diagnostics not only show who is victimized but also whether the victims are bullied by the same bully or multiple bullies. Those who are bullied by many bullies often report lower school well-being and are more rejected and less accepted by classmates (Van der Ploeg et al. 2015). Those victims are also likely to be more vulnerable to for future victimization because they are targeted by a broader range of peers (Nishina 2012).

Combining information on victimization and bullying can also help in identifying bully-victims, who are a distinct group of students in terms of health correlates (Lereya et al. 2015). Bully-victims often come from the most adverse home environments (Cook et al. 2010; Lereya et al. 2013), experience greater

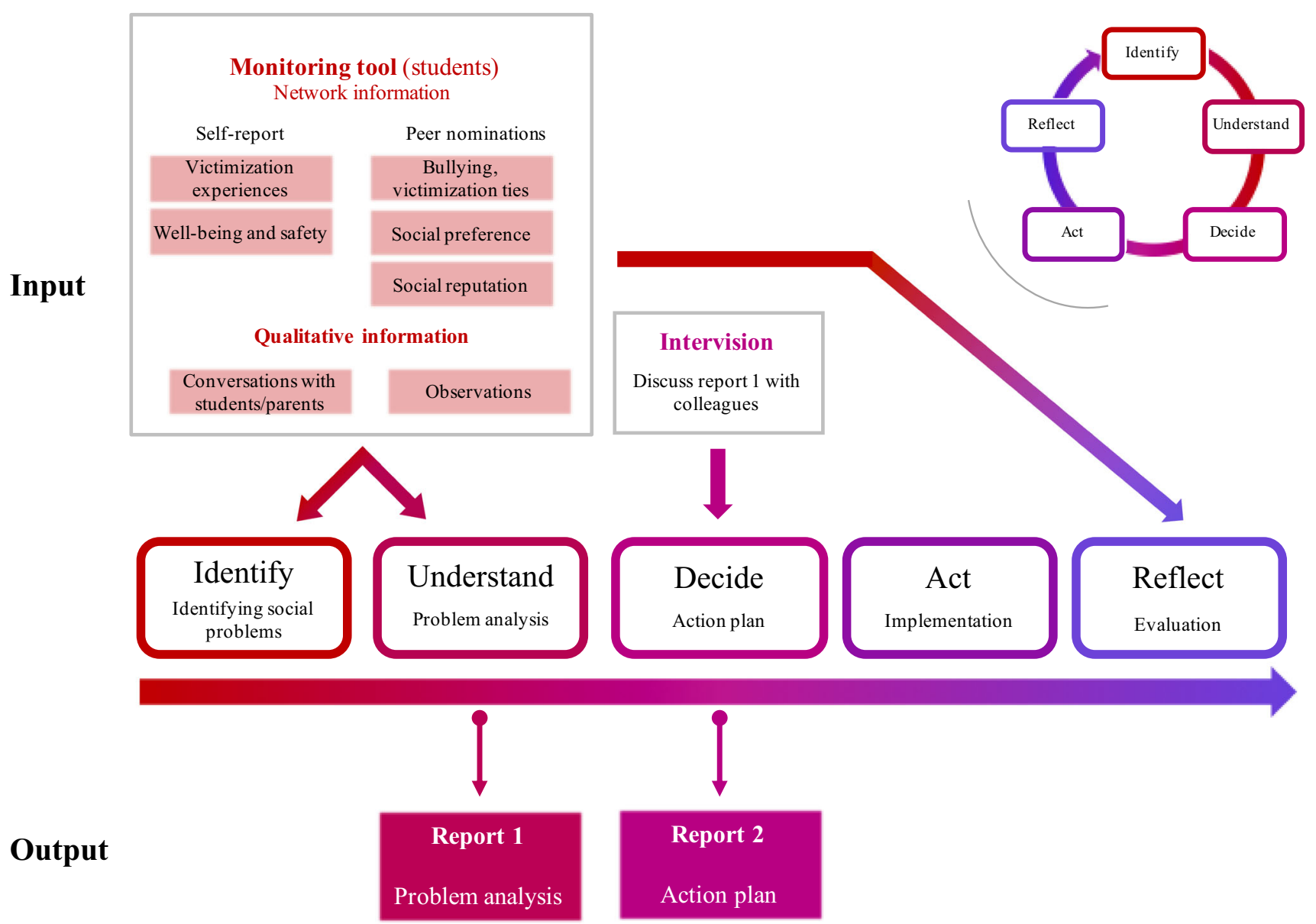

Fig. 2 Model of systematic interpretation of network diagnostics by teachers across a school year. Reverse processes (e.g., collection of more qualitative information after identifying problems) are not visualized for ease of interpretation 
aggression problems, and show a different socio-cognitive profile compared with pure bullies (e.g., Toblin et al. 2005).

Social Position Information on bullying and victimization can be complemented with information on students' social position, thus their social relationships and relative position in the group (friendships, acceptance, rejection). These diagnostics can be used to recognize socially vulnerable students who could be at risk for victimization because of their weak social position (Neal et al. 2011; Oldenburg et al. 2016). Particularly worrisome are students who do not have friends or are not accepted by many classmates. Those marginalized students are ignored by many classmates, receive little affection and support, and are therefore easier targets for bullies (Juvonen and Graham 2014). These students will also suffer the most because classmates are less likely to help them process their experiences (Huitsing et al. 2019). Rejected students deserve attention as well, because they are attractive targets for bullies and often receive little support (Sentse et al. 2017). Their situation is also not always recognized when their provocative behavior masks their problems (Asher and McDonald 2009). Hence, these diagnostics enable teachers to understand the situation of vulnerable students whose negative position may otherwise be overlooked.

Students' Well-Being at School Students' self-reported wellbeing at school can complement the relationship information, by providing an indication of the perceived severity of their (social) problems (Loukas and Pasch 2013). It sheds light on students' experienced safety in the classroom and their feelings and experiences on a typical school day. This is also relevant because marginalized students with low school well-being are in greater need of help than those who still enjoy going to school (Loukas and Pasch 2013; You et al. 2008). Moreover, low school well-being is associated with maladjustment symptoms (Aldridge and McChesney 2018), which are risk factors for persistent victimization (Brendgen et al. 2016; Kaufman et al. 2018).

Example We illustrate how the diagnostics can be used to identify problems in step 1 with a hypothetical example, based on Table 1 and Fig. 1. Table 1 shows that one student, Sophie, reports both systematic victimization and low school well-being, indicating that her situation may be problematic. She has no best friends and is liked by only two classmates. The sociogram in Fig. 1 shows that Sophie selected four classmates as bullies; these are befriended with each other. The students whom she nominated as bullies (Anna, Isaac, Ethan, and Elijah) were also nominated by four other classmates as bullies (by Nyen, Zyaire, Mason, and Jacob), who indicated having been victimized once or twice. Sophie also reported that she was befriended with one of these victims (Nyen), but this friendship was not reciprocated. The other victims also nominated each other as friends and thus form a subgroup of victims. Anna was named most often as a bully by three of these students.

Based on this information, the teacher can decide to continue with the intervention cycle (steps 2-5) to better understand Sophie's situation and decide about actions to stop the victimization. Other students who are potentially in need of support are Liz (rejected, without friends, and not liked), Zyaire (victimized), Ethan (rejected, very low well-being, and bullying others), and the other students who received bullying nominations (Isaac, Anna, and Elijah).

\section{Step 2: Understand}

The understand step urges teachers to analyze the specific situation of the victims and the group. The aggregated diagnostics of the victims' social preferences and friendships help teachers to understand their social situations: whether victims have a negative position (referring to who also bullies or is rejected) or positive position (referring to who is accepted or has many friends) in the classroom (De Bruyn et al. 2009). Moreover, information about reputation (prosocial behavior, popularity, leadership), thus individuals' social impact in the peer group (Cillessen and Mayeux 2004; Dijkstra et al. 2008), can be valuable to understand why the bullying persists. If bullies are popular students or are considered good leaders, this means that they have a high social impact on others and that it is unlikely that peers would dare to defend their $\operatorname{victim}(\mathrm{s})$, because defending would put their own status at risk (Garandeau et al. 2014a; Huitsing et al. 2014; Pöyhönen et al. 2010; Salmivalli 2010). Thus, diagnostics of the bullies' reputation can explain why the bullying persists.

Teachers can complement the network diagnostics with qualitative information, by discussing the situation with the victim, bullies, potential defenders, or outsiders, and by observing the situation more closely. In addition, speaking with the victim's parents can be valuable if the victim permits it. Parent-child interactions such as the presence or absence of parental warmth can play an important role in explaining persistent victimization processes (Bowes et al. 2013; Brendgen et al. 2016; Kaufman et al. 2020) and, therefore, need to be considered when handling the problem.

Example In the hypothetical data shown in Table 1 and Fig. 1, the diagnostics show that victim Sophie has a marginalized position, because she is not nominated as a friend and is only liked by a few students, which can make it easier for bullies to target her. Most bullies are popular but not well-liked and even rejected by many students, except for Anna. She is also named as a friend by many peers and is considered a leader. 


\section{Steps 3 and 4: Decide and Act}

After this problem analysis, teachers are encouraged to think about potential actions and decide which one fits the situation best. Explicating this step encourages teachers to tailor actions to the situation, by considering elements of the group structure such as the victims' position in the peer group, instead of hurriedly taking action that may prove inappropriate. The decision should result in a concrete action plan: what is the concrete goal, what actions will be taken, how, when, and by whom? Making an explicit action plan enhances feelings of internal control and responsibility, because action plans are associated with setting explicit goals and making concrete plans (Schunk 1990). The plans may help teachers to claim their central role in handling the observed problem and to take the lead in tackling it (Ellis and Shute 2007). In addition, individuals are more likely to take action when they set concrete goals and have made plans to do so, in order to reduce "cognitive dissonance" (Festinger 1962), the mental discomfort that individuals experience when they act inconsistently with their plans or ideas.

Teachers first make an action plan in step 3 (decide) and then take action in step 4 (act). To decide about the actions, and which of the students will be involved, they can use the network diagnostics again. The diagnostics cannot dictate which actions need to be taken, because every situation calls for a different solution, and there is no blueprint for addressing bullying problems. However, the diagnostics inform teachers about the peer context of the problem, which can help them to decide about the actions and which students they should target (Valente 2012).

Bullying and Victimization Information on the total number of victims and bullies can be informative in deciding about actions. When one person is being bullied by multiple peers, it seems effective to take actions focused on the victim's situation. Examples include actions that target subgroups of peers to increase support for the victim, using the support group approach (Van der Ploeg et al. 2016), which is similar to the method of shared concern (Pikas 2002) or the no-blame approach (Robinson and Maines 2008). The purpose of the support group is not to blame the bullies but to create a shared concern for the well-being of the victim. It is assumed that the shared distress will evoke empathy in the bullies and that the social pressure or shared responsibility will encourage the bullies to alter their behavior, and peers are expected to lose the excitement and arousal of watching bullying (Rigby 2014; Robinson and Maines 2008; Young 1998).

If victims are experiencing severe individual or social adjustment problems or problems at home, they can benefit from individual approaches (Bradshaw 2013), such as a training course focused on improving their self-esteem, practicing social skills, acquiring a more positive mindset (Yeager et al.
2013), or involving their parents (Healy and Sanders 2014). Bully-victims may especially need such approaches because of their greater risk of individual and social adjustment problems and problems at home, as explained above.

If multiple victims are bullied by the same group of bullies, teachers may choose actions that confront the bullies with their behavior. An example is the confronting approach used in the KiVa program (Garandeau et al. 2014a, 2014b), in which the bullies are held openly responsible for their behavior and are asked to think about ways to improve the victims' situation. The most optimal approach might be a combination of confronting (e.g., blaming bullies specifically for their behavior) and non-confronting (e.g., increasing empathy for victims) elements (Garandeau et al. 2016).

Last, when there are multiple bullies and victims, or when victims bully each other, the entire social climate seems disrupted, and teachers can decide to implement a wholegroup approach, such as a conversation with the entire group or activities that are part of a school-wide intervention program focused on improving the classroom atmosphere (Evans et al. 2014; Lund et al. 2012).

Social Position Information on social preferences, friendships, and reputation can also be valuable in deciding about and tailoring actions to the situation. For example, marginalized victims of bullying can benefit from the above-described actions (e.g., the support group) that target subgroups to provide victims with more supportive and affective peer relations. In addition, the information about students' reputations clarifies which students, including bullies, have a greater social impact, and are thus "norm-setters" (Dijkstra et al. 2008; Sentse et al. 2015). If these high-impact students are targeted with interventions to support victims and stop or discourage bullying, the classroom norm can change into one that no longer considers bullying as a means to achieve status (Paluck and Shepherd 2012; Peets et al. 2015). However, teachers should verify that the targeted students are sufficiently motivated to be involved in actions to change the norms; high-impact students do not always want to invest in change in the group dynamics or norms, because they have a vested interest in the status quo (Valente 2012).

Example In the example given, the teacher's goals can be to increase social support for Sophie, given her potentially marginalized position, and to decrease the bullies' motivation to continue bullying. The goal is achieved when Sophie has at least one friendship and when the four bullies have stopped their detrimental behavior. The teacher can decide to implement the support group approach.

The network diagnostics can help in deciding about the composition of the support group. The support group preferably consists of the most influential bully, the defenders or friends of the victim, and prosocial, high-status peers (Van 
der Ploeg et al. 2016). It would be important to include the bullying girl, Anna, who is liked by many classmates and at the same time befriended with the other bullies, and to include Anna's friends Jayden and Olivia who do not participate in the bullying process. Further, the teacher can involve Jazz and Debby, who are popular, prosocial students and who are not involved in the bullying process; they can be asked to support Sophie and set a clear anti-bullying norm.

\section{Step 5: Reflect}

Last, reflecting on the actions and their effectiveness in improving the victims' situation is an essential and increasingly required part of teachers' professionalization, because it facilitates internal analyses of their own effectiveness in tackling bullying (Mann et al. 2009). Reflection contributes to professionals' learning processes and awareness of the effects of their practices (Bandura 1986). Teachers verify through their reflection whether their goals have been reached and whether further improvement is needed. This reflection is based first on qualitative information, such as conversations with victims and the peers who were involved in the actions or the broader peer group. This information can be confirmed with new network information; these new contributions to the reflection process can give further directions for a potential new intervention cycle, starting with step 1 .

Example The teacher in the example can evaluate the effects of the actions through conversations with Sophie and the students in the support group, and complement this information with new network diagnostics that show whether Sophie's friendships and acceptance by peers have improved and whether the bullying has stopped.

\section{Conclusions, Limitations, and Directions for Future Research}

We have proposed that persistent victimization might be prevented or stopped by providing teachers with network information, because this information has the potential to help teachers to recognize victimization earlier and to respond to it with tailored actions (Haataja et al. 2015b). Information on bullying and victimization, students' social position (friendships, social preferences, and social reputation), and school well-being can help in understanding how bullying processes are embedded in the classroom context. This information enables teachers to target the most relevant students for actions rather than the entire peer group (Dijkstra et al. 2008; Gesell et al. 2013; Huitsing and Veenstra 2012; Valente et al. 2007). Teachers can handle the abstract information by using the five-step intervention cycle (identifying, understanding, explaining, taking action, reflecting), which results in a concrete problem analysis and action plan for every systematic victim. This approach can (1) stimulate a structural focus among teachers on early recognition of victims, (2) lead to more prompt actions that are tailored to the classroom and victims' situations, and (3) result in structured overviews of how teachers handle problems, which can be useful for future problems or other colleagues.

Despite these potential strengths, our proposal also has limitations. First, relational information cannot capture all parameters that affect group dynamics. For example, victims' internalizing symptoms or problems in their relationships with parents could be risk factors for being persistently victimized (Bowes et al. 2013; Brendgen et al. 2016; Kaufman et al. 2018) but are not fully captured in the proposed diagnostics. However, a monitor for students should be practical to assess, including too many questions could increase the duration of filling in the monitor and can make the collected information less reliable. Information on school well-being could serve as a first indicator of internalizing symptoms, and teachers could further inquire about these symptoms when talking with victims. Similarly, the role of parents is preferably examined through direct conversations instead of diagnostics. Thus, quantitative diagnostics should serve as a starting point to shed light on processes that may otherwise be overlooked. This information may be complemented by observations and conversations with students.

Last, schools may consider lack of time or resources as a barrier to using the approach. For this reason, it may be emphasized that implementing the intervention cycle should not take additional time because this approach only explicates and structures those steps that teachers have always had to take when addressing problems. Moreover, the approach can lead to more efficient actions by targeting the most relevant peers in the bullying process. Nevertheless, using an online tool requires additional administration and planning. Teachers need to be trained in using the tool and need expert support to gain understanding of the use of network diagnostics. These activities could all be experienced as barriers in terms of time and resources and therefore need to be considered carefully before using the tool. To reduce the required workload, it is important that schools appoint a central coordinator who ensures that all teachers are sufficiently informed about the use of the approach, reminds them about the actions that need to be taken, and arranges training courses (Sainio et al. 2018). Central coordination may limit the additional workload for teachers.

Future research is needed to examine whether, and for whom, the systematic use of network diagnostics is effective. This research could first take the form of a pilot study to test the feasibility of the approach in a small number of schools that can provide extensive input. The pilot could be followed up by experimental research to test its effects on a larger scale. A first question that needs to be addressed is does this approach help to improve teachers' recognition of and tailored 
responses to bullying, and does it contribute to reductions in bullying? Second, the approach may not be effective for some teachers, schools, or students. Teachers who are not sufficiently trained in implementing actions to reduce bullying, who have lower anti-bullying attitudes, or who have few resources, such as principal support (Haataja et al. 2015a; Sainio et al. 2018), may experience more difficulty implementing the approach.

The type of school, primary or secondary, may also affect the results. Our proposal described how teachers in primary schools could use the systematic approach, but it might also work in secondary schools. Bullying becomes subtler and more indirect with age and thus harder to detect through observation (Yeager et al. 2015); diagnostics might help in detecting it. Moreover, the components of the monitoring tool focus on social dynamics, such as social status, that become increasingly important in adolescence (Dahl et al. 2018). A precondition for the successful use of network diagnostics is that the teacher knows the class well and can help to guide group processes; this is not always the case in secondary schools. Last, child-related factors can affect the successful implementation of a monitoring tool to collect diagnostics. Children in early elementary school or students with reading problems can be presented with pictures instead of text and be instructed through a headset (Verlinden et al. 2014).

Overall, it would thus be fruitful to examine whether teacher-, school-, or child-related factors moderate the effects of the systematic use of network diagnostics. This research is needed to explore a promising method that aids teachers in the daily practice of signaling and tackling bullying in schools and preventing persistent victimization.

Funding Information This research is funded by the Dutch Science Foundation (NWO VICI 453-14-016; NWO VENI 451-17-013).

\section{Compliance with Ethical Standards}

Conflict of Interest The authors contributed to the coordination, programming, development, and implementation of the online tool for Dutch primary and secondary schools. The systematic stepwise approach has been programmed but not yet implemented. Dissemination of the online tool is done by separate companies (SocioQuest, KiVa-NL). The third author (Rick Bloemberg) works for KiVa-NL, but none of the authors has financial interest or other conflicts of interest.

Open Access This article is licensed under a Creative Commons Attribution 4.0 International License, which permits use, sharing, adaptation, distribution and reproduction in any medium or format, as long as you give appropriate credit to the original author(s) and the source, provide a link to the Creative Commons licence, and indicate if changes were made. The images or other third party material in this article are included in the article's Creative Commons licence, unless indicated otherwise in a credit line to the material. If material is not included in the article's Creative Commons licence and your intended use is not permitted by statutory regulation or exceeds the permitted use, you will need to obtain permission directly from the copyright holder. To view a copy of this licence, visit http://creativecommons.org/licenses/by/4.0/.

\section{References}

Aldridge, J. M., \& McChesney, K. (2018). The relationships between school climate and adolescent mental health and wellbeing: a systematic literature review. International Journal of Educational Research, 88, 121-145. https://doi.org/10.1016/j.ijer.2018.01.012.

Antoniadou, N., Kokkinos, C. M., \& Fanti, K. A. (2019). Traditional and cyber bullying/victimization among adolescents: examining their psychosocial profile through latent profile analysis. International Journal of Bullying Prevention, 1, 85-98. https://doi.org/10.1007/ s42380-019-00010-0.

Asher, S. R., \& McDonald, K. L. (2009). The behavioral basis of acceptance, rejection, and perceived popularity. In K. H. Rubin, W. M. Bukowski, \& B. Laursen (Eds.), Handbook of peer interactions, relationships, and groups (pp. 232-248). New York: Guilford.

Bandura, A. (1986). Social foundations of thought and action: a social cognitive theory. Englewood Cliffs, NJ: Prentice Hall.

Bowes, L., Maughan, B., Ball, H., Shakoor, S., Ouellet-Morin, I., Caspi, A., Moffitt, T. E., \& Arseneault, L. (2013). Chronic bullying victimization across school transitions: the role of genetic and environmental influences. Development and Psychopathology, 25, 333-346. https://doi.org/10.1017/S0954579412001095.

Bradshaw, C. P. (2013). Preventing bullying through positive behavioral interventions and supports (PBIS): a multitiered approach to prevention and integration. Theory Into Practice, 52, 288-295. https://doi. org/10.1080/00405841.2013.829732.

Brendgen, M., \& Poulin, F. (2018). Continued bullying victimization from childhood to young adulthood: a longitudinal study of mediating and protective factors. Journal of Abnormal Child Psychology, 46, 27-39. https://doi.org/10.1007/s10802-017-0314-5.

Brendgen, M., Girard, A., Vitaro, F., Dionne, G., \& Boivin, M. (2016). Personal and familial predictors of peer victimization trajectories from primary to secondary school. Developmental Psychology, 52, 1103-1114. https://doi.org/10.1037/dev0000107.

Campbell, M., Whiteford, C., \& Hooijer, J. (2019). Teachers' and parents' understanding of traditional and cyberbullying. Journal of School Violence, 18, 388-402. https://doi.org/10.1080/15388220.2018. 1507826.

Cillessen, A. H. N., \& Mayeux, L. (2004). From censure to reinforcement: developmental changes in the association between aggression and social status. Child Development, 75, 147-163. https://doi.org/ 10.1111/j.1467-8624.2004.00660.x.

Coie, J. D., Dodge, K. A., \& Coppotelli, H. (1982). Dimensions and types of social status: a cross-age perspective. Developmental Psychology, 19, 224. https://doi.org/10.1037/0012-1649.19.2.224.

Cook, C. R., Williams, K. R., Guerra, N. G., Kim, T. E., \& Sadek, S. (2010). Predictors of bullying and victimization in childhood and adolescence: a meta-analytic investigation. School Psychology Quarterly, 25, 65-83. https://doi.org/10.1037/a0020149.

Cornell, D., \& Limber, S. P. (2015). Law and policy on the concept of bullying at school. American Psychologist, 70, 333-343. https://doi. org/10.1037/a0038558.

Cunningham, C. E., Rimas, H., Vaillancourt, T., Stewart, B., Deal, K., Cunningham, L., et al. (2019). What antibullying program designs motivate student intervention in grades 5 to 8? Journal of Clinical Child and Adolescent Psychology. https://doi.org/10.1080/ 15374416.2019.1567344.

Dahl, R. E., Allen, N. B., Wilbrecht, L., \& Suleiman, A. B. (2018). Importance of investing in adolescence from a developmental science perspective. Nature, 554, 441-450. https://doi.org/10.1038/ nature 25770 .

De Bruyn, E. H., Cillessen, A. H. N., \& Wissink, I. B. (2009). Associations of peer acceptance and perceived popularity with 
bullying and victimization in early adolescence. The Journal of Early Adolescence, 30, 543-566.

De Shazer, S., \& Dolan, Y. (2007). More than miracles: the state of the art of solution-focused brief therapy. Binghamton, NY: The Haworth Press.

Deming, W. (1989). Out of the crisis. Cambridge: Massachusetts Insitute of Technology Center for Advanced Engineering Studies.

Dijkstra, J. K., Lindenberg, S., \& Veenstra, R. (2008). Beyond the class norm: bullying behavior of popular adolescents and its relation to peer acceptance and rejection. Journal of Abnormal Child Psychology, 36, 1289-1299. https://doi.org/10.1007/s10802-0089251-7.

Ellis, A. A., \& Shute, R. (2007). Teacher responses to bullying in relation to moral orientation and seriousness of bullying. British Journal of Educational Psychology, 77, 649-663. https://doi.org/10.1348/ 000709906 X163405.

Evans, C. B. R., Fraser, M. W., \& Cotter, K. L. (2014). The effectiveness of school-based bullying prevention programs: a systematic review. Aggression and Violent Behavior, 19, 532-544. https://doi.org/10. 1016/j.avb.2014.07.004.

Farmer, T. W., Farmer, E. M., Estell, D. B., \& Hutchins, B. C. (2007). The developmental dynamics of aggression and the prevention of school violence. Journal of Emotional and Behavioral Disorders, 15, 197 208.

Fekkes, M., Pijpers, F. I. M., \& Verloove-Vanhorick, S. P. (2005). Bullying: Who does what, when and where? Involvement of children, teachers and parents in bullying behavior. Health Education Research, 20, 81-91. https://doi.org/10.1093/her/cyg100.

Felix, E. D., Sharkey, J. D., Green, J. G., Furlong, M. J., \& Tanigawa, D. (2011). Getting precise and pragmatic about the assessment of bullying: the development of the California bullying victimization scale. Aggressive Behavior, 37, 234-247. https://doi.org/10.1002/ ab.20389.

Festinger, L. (1962). Cognitive dissonance. Scientific American, 207, 93 106. https://doi.org/10.1038/scientificamerican1062-93.

Furlong, M. J., Sharkey, J. D., Felix, E. D., Tanigawa, D., \& Green, J. G. (2010). Bullying assessment: a call for increased precision of selfreported procedures. In S. R. Jimerson, S. M. Swearer, \& D. L. Espelage (Eds.), Handbook of bullying in schools: an international perspective (pp. 329-345). New York: Routledge.

Gaffney, H., Ttofi, M. M., \& Farrington, D. P. (2019). Evaluating the effectiveness of school-bullying prevention programs: an updated meta-analytical review. Aggression and Violent Behavior, 45, 111133. https://doi.org/10.1016/j.avb.2018.07.001.

Garandeau, C. F., Lee, I. a., \& Salmivalli, C. (2014a). Differential effects of the KiVa anti-bullying program on popular and unpopular bullies. Journal of Applied Developmental Psychology, 35(1), 44-50. https://doi.org/10.1016/j.appdev.2013.10.004.

Garandeau, C. F., Poskiparta, E., \& Salmivalli, C. (2014b). Tackling acute cases of school bullying in the KiVa anti-bullying program: a comparison of two approaches. Journal of Abnormal Child Psychology, 42, 981-991. https://doi.org/10.1007/s10802-014-9861-1.

Garandeau, C. F., Vartio, A., Poskiparta, E., \& Salmivalli, C. (2016). School bullies' intention to change behavior following teacher interventions: effects of empathy arousal, condemning of bullying, and blaming of the perpetrator. Prevention Science, 17(8), 1034 1043. https://doi.org/10.1007/s11121-016-0712-x.

Gesell, S. B., Barkin, S. L., \& Valente, T. W. (2013). Social network diagnostics: a tool for monitoring group interventions. Implementation Science, 8, 116-127. https://doi.org/10.1186/17485908-8-116.

Gest, S. D., Osgood, D. W., Feinberg, M. E., Bierman, K. L., \& Moody, J. (2011). Strengthening prevention program theories and evaluations: contributions from social network analysis. Prevention Science, 12, 349-360. https://doi.org/10.1007/s11121-011-0229-2.
Haataja, A., Voeten, M., Boulton, A. J., Ahtola, A., Poskiparta, E., \& Salmivalli, C. (2014). The KiVa antibullying curriculum and outcome: does fidelity matter? Journal of School Psychology, 52, 479493. https://doi.org/10.1016/j.jsp.2014.07.001.

Haataja, A., Ahtola, A., Poskiparta, E., \& Salmivalli, C. (2015a). A process view on implementing an antibullying curriculum: how teachers differ and what explains the variation. School Psychology Quarterly, 3, 564-576. https://doi.org/10.1037/spq0000121.

Haataja, A., Sainio, M., Turtonen, M., \& Salmivalli, C. (2015b). Implementing the KiVa antibullying program: recognition of stable victims. Educational Psychology, 36, 595-611. https://doi.org/10. 1080/01443410.2015.1066758.

Healy, K. L., \& Sanders, M. R. (2014). Randomized controlled trial of a family intervention for children bullied by peers. Behavior Therapy, 45, 760-777. https://doi.org/10.1016/j.beth.2014.06.001.

Huitsing, G., \& Veenstra, R. (2012). Bullying in classrooms: participant roles from a social network perspective. Agressive Behavior, 38, 494-509. https://doi.org/10.1002/ab.21438.

Huitsing, G., Snijders, T. A. B., Van Duijn, M. A. J., \& Veenstra, R. (2014). Victims, bullies, and their defenders: a longitudinal study of the coevolution of positive and negative networks. Development and Psychopathology, 26, 645-659. https://doi.org/10.1017/ S0954579414000297.

Huitsing, G., Lodder, G. M. A., Oldenburg, B., Schacter, H. L., Salmivalli, C., Juvonen, J., \& Veenstra, R. (2019). The healthy context paradox: victims' adjustment during an anti- bullying intervention. Journal of Child and Family Studies, 28, 2499-2509. https:// doi.org/10.1007/s10826-018-1194-1.

Juvonen, J., \& Graham, S. (2014). Bullying in schools: the power of bullies and the plight of victims. Annual Review of Psychology, 65, 159-185. https://doi.org/10.1146/annurev-psych-010213115030.

Juvonen, J., \& Ho, A. Y. (2008). Social motives underlying antisocial behavior across middle school grades. Journal of Youth and Adolescence, 37, 747-756. https://doi.org/10.1007/s10964-0089272-0.

Kärnä, A., Voeten, M., Little, T. D., Poskiparta, E., Kaljonen, A., \& Salmivalli, C. (2011). A large-scale evaluation of the KiVa antibullying program: grades 4-6. Child Development, 82, 311330. https://doi.org/10.1111/j.1467-8624.2010.01557.x.

Kaufman, T. M. L., Huitsing, G., \& Veenstra, R. (2020). Refining victims' self-reports on bullying: assessing frequency, intensity, power imbalance, and goal- directedness. Social Development. https://doi. org/10.1111/sode. 12441

Kaufman, T. M. L., Kretschmer, T., Huitsing, G., \& Veenstra, R. (2018). Why does a universal anti-bullying program not help all children? Explaining persistent victimization during an intervention. Prevention Science, 19, 822-832. https://doi.org/10.1007/s11121018-0906-5.

Kaufman, T. M. L., Kretschmer, T., Huitsing, G., \& Veenstra, R. (2020). Caught in a vicious cycle? Explaining bidirectional spillover between parent-child relationships and peer victimization. Development and Psychopathology. https://doi.org/10.1017/ S0954579418001360.

Kok, G., Gottlieb, N. H., Peters, G. J. Y., Mullen, P. D., Parcel, G. S., Ruiter, R. A. C., et al. (2016). A taxonomy of behaviour change methods: an intervention mapping approach. Health Psychology Review, 10, 297-312. https://doi.org/10.1080/17437199.2015. 1077155 .

Lereya, S. T., Samara, M., \& Wolke, D. (2013). Parenting behavior and the risk of becoming a victim and a bully/victim: a meta-analysis study. Child Abuse \& Neglect, 37, 1091-1108. https://doi.org/10. 1016/j.chiabu.2013.03.001.

Lereya, S. T., Copeland, W. E., Zammit, S., \& Wolke, D. (2015). Bully/ victims: a longitudinal, population-based cohort study of their 
mental health. European Child and Adolescent Psychiatry, 24, 1461-1471. https://doi.org/10.1007/s00787-015-0705-5.

Loukas, A., \& Pasch, K. E. (2013). Does school connectedness buffer the impact of peer victimization on early adolescents' subsequent adjustment problems? Journal of Early Adolescence, 33, 245-266. https://doi.org/10.1177/0272431611435117.

Lund, E. M., Blake, J. J., Ewing, H. K., \& Banks, C. S. (2012). School counselors' and school psychologists' bullying prevention and intervention strategies: a look into real-world practices. Journal of School Violence, 11, 246-265. https://doi.org/10.1080/15388220. 2012.682005 .

Madden, T. J., Ellen, P. M., \& Ajzen, I. (1992). A comparison of the theory of planned behavior and the theory of reasoned action. Personality and Social Psychology Bulletin, 18, 3-9.

Mann, K., Gordon, J., \& MacLeod, A. (2009). Reflection and reflective practice in health professions education: a systematic review. Advances in Health Sciences Education, 14, 595-621. https://doi. org/10.1007/s10459-007-9090-2.

Matsuo, M., \& Nakahara, J. (2013). The effects of the PDCA cycle and OJT on workplace learning. International Journal of Human Resource Management, 24, 195-207. https://doi.org/10.1080/ 09585192.2012.674961.

Neal, J. W., Cappella, E., Wagner, C., \& Atkins, M. S. (2011). Seeing eye to eye: predicting teacher-student agreement on classroom social networks. Social Development, 20, 376-393. https://doi.org/10. 1111/j.1467-9507.2010.00582.x.

Nishina, A. (2012). Microcontextual characteristics of peer victimization experiences and adolescents' daily well-being. Journal of Youth and Adolescence, 41, 191-201. https://doi.org/10.1007/s10964-0119669-z.

Oldenburg, B., Bosman, R., \& Veenstra, R. (2016). Are elementary school teachers prepared to tackle bullying? A pilot study. School Psychology International, 37, 64-72.

Olthof, T., Goossens, F. A., Vermande, M. M., Aleva, E. A., \& Van der Meulen, M. (2011). Bullying as strategic behavior: relations with desired and acquired dominance in the peer group. Journal of School Psychology, 49, 339-359. https://doi.org/10.1016/j.jsp.2011.03.003.

Olweus, D. (1993). Bullying at school: what we know and what we can do. Malden, MA: Blackwell Publishing.

Paluck, E. L., \& Shepherd, H. (2012). The salience of social referents: a field experiment on collective norms and harassment behavior in a school social network. Journal of Personality and Social Psychology, 103, 899-915. https://doi.org/10.1037/a0030015.

Paluck, E. L., Shepherd, H., \& Aronow, P. M. (2018). Changing climates of conflict: A social network experiment in 56 schools. Proceedings of the National Academy of Sciences, 115, E3598. https://doi.org/10. 1073/pnas.1804429115.

Peets, K., Pöyhönen, V., Juvonen, J., \& Salmivalli, C. (2015). Classroom norms of bullying alter the degree to which children defend in response to their affective empathy and power. Developmental Psychology, 51, 913-920. https://doi.org/10.1037/a0039287.

Pikas, A. (2002). New developments of the shared concern method. School Psychology International, 23, 307-326.

Pöyhönen, V., Juvonen, J., \& Salmivalli, C. (2010). What does it take to stand up for the victim of bullying? The interplay between personal and social factors. Merrill-Palmer Quarterly, 56, 143-163. https:// doi.org/10.1353/mpq.0.0046.

Rambaran, J. A., Dijkstra, J. K., \& Veenstra, R. (2019). Bullying as a group process in childhood: a longitudinal social network analysis. Child Development. https://doi.org/10.1111/cdev.13298.

Rigby, K. (2014). How teachers address cases of bullying in schools: a comparison of five reactive approaches. Educational Psychology in Practice, 30, 409-419. https://doi.org/10.1080/02667363.2014. 949629.

Robinson, G., \& Maines, B. (2008). Bullying: a complete guide to the support group method. London: Sage.
Saarento, S., Boulton, A. J., \& Salmivalli, C. (2015). Reducing bullying and victimization: Student- and classroom-level mechanisms of change. Journal of Abnormal Child Psychology, 43, 61-76. https://doi.org/10.1007/s10802-013-9841-x.

Sainio, M., Veenstra, R., Huitsing, G., \& Salmivalli, C. (2011). Victims and their defenders: a dyadic approach. International Journal of Behavioral Development, 35, 144-151. https://doi.org/10.1177/ 0165025410378068

Sainio, M., Herkama, S., Turunen, T., Rönkkö, M., Kontio, M., Poskiparta, E., \& Salmivalli, C. (2018). Sustainable antibullying program implementation: school profiles and predictors. Scandinavian Journal of Psychology. https://doi.org/10.1111/sjop. 12487.

Salmivalli, C. (2010). Bullying and the peer group: a review. Aggression and Violent Behavior, 15, 112-120. https://doi.org/10.1016/j.avb. 2009.08.007.

Salmivalli, C., Voeten, M., \& Poskiparta, E. (2011). Bystanders matter: associations between reinforcing, defending, and the frequency of bullying behavior in classrooms. Journal of Clinical Child and Adolescent Psychology, 40, 668-676. https://doi.org/10.1080/ 15374416.2011.597090.

Schunk, D. H. (1990). Goal setting and self-efficacy during self-regulated learning. Educational Psychologist, 25, 71-86.

Sentse, M., Veenstra, R., Kiuru, N., \& Salmivalli, C. (2015). A longitudinal multilevel study of individual characteristics and classroom norms in explaining bullying behaviors. Journal of Abnormal Child Psychology, 43, 943-955. https://doi.org/10.1007/s10802014-9949-7.

Sentse, M., Prinzie, P., \& Salmivalli, C. (2017). Testing the direction of longitudinal paths between victimization, peer rejection, and different types of internalizing problems in adolescence. Journal of Abnormal Child Psychology, 45, 1013-1023. https://doi.org/10. 1007/s10802-016-0216-y.

Shewhart, W. A. (1939). Statistical method from the viewpoint of quality control. Washington, DC: The Graduate School, Department of Agriculture.

Sijtsema, J. J., Veenstra, R., Lindenberg, S., \& Salmivalli, C. (2009). Empirical test of bullies' status goals: assessing direct goals, aggression, and prestige. Aggressive Behavior, 35, 57-67. https://oi.org/ 10.1002/ab.20282.

Smit, C. R., De Leeuw, R. N. H., Bevelander, K. E., Burk, W. J., \& Buijzen, M. (2016). A social network-based intervention stimulating peer influence on children's self-reported water consumption: a randomized control trial. Appetite, 103, 294-301. https://doi.org/10. 1016/j.appet.2016.04.011.

Solberg, M. E., \& Olweus, D. (2003). Prevalence estimation of school bullying with the Olweus bully/victim questionnaire. Aggressive Behavior, 29, 239-268. https://doi.org/10.1002/ab.10047.

Toblin, R. L., Schwartz, D., Gorman, A. H., \& Abou-Ezzeddine, T. (2005). Social-cognitive and behavioral attributes of aggressive victims of bullying. Journal of Applied Developmental Psychology, 26, 329-346. https://doi.org/10.1016/j.appdev.2005.02.004.

UNESCO. (2017). School violence and bullying: global status report.

Valente, T. W. (2012). Network interventions. Science, 337, 49-53. https://doi.org/10.1126/science.1217330.

Valente, T. W., \& Pitts, S. R. (2017). An appraisal of social network theory and analysis as applied to public health: challenges and opportunities. Annual Review of Public Health, 38, 103-118. https:// doi.org/10.1146/annurev-publhealth-031816-044528.

Valente, T. W., Ritt-Olson, A., Stacy, A., Unger, J. B., Okamoto, J., \& Sussman, S. (2007). Peer acceleration: Effects of a social network tailored substance abuse prevention program among high-risk adolescents. Addiction, 102, 1804-1815. https://doi.org/10.1111/j. 1360-0443.2007.01992.x.

Van der Ploeg, R., Steglich, C., Salmivalli, C., \& Veenstra, R. (2015). The intensity of victimization: associations with children's psychosocial 
well-being and social standing in the classroom. PLoS One, 10, 115. https://doi.org/10.1371/journal.pone.0141490.

Van der Ploeg, R., Steglich, C., \& Veenstra, R. (2016). The support group approach in the Dutch KiVa anti-bullying programme: effects on victimisation, defending and well-being at school. Educational Research, 58, 221-236. https://doi.org/10.1080/00131881.2016. 1184949.

Van Der Ploeg, R., Steglich, C., \& Veenstra, R. (2020). The way bullying works: how new ties facilitate the mutual reinforcement of status and bullying in elementary schools. Social Networks, 60, 71-82. https:// doi.org/10.1016/j.socnet.2018.12.006.

Van Waes, S., De Maeyer, S., Moolenaar, N. M., Van Petegem, P., \& Van den Bossche, P. (2018). Strengthening networks: a social network intervention among higher education teachers. Learning and Instruction, 53, 34-49. https://doi.org/10.1016/j.learninstruc.2017. 07.005 .

Veenstra, R., Lindenberg, S., Oldehinkel, A. J., De Winter, A. F., Verhulst, F. C., \& Ormel, J. (2005). Bullying and victimization in elementary schools: a comparison of bullies, victims, bully/victims, and uninvolved preadolescents. Developmental Psychology, 41, 672-682. https://doi.org/10.1037/0012-1649.41.4.672.

Veenstra, R., Lindenberg, S., Munniksma, A., \& Dijkstra, J. (2010). The complex relation between bullying, victimization, acceptance, and rejection: Giving special attention to status, affection, and sex differences. Child Development, 81, 480-486. https://doi.org/10.1111/ j.1467-8624.2009.01411.x.

Verlinden, M., Veenstra, R., Ringoot, A. P., Jansen, P. W., Hofman, A., Jaddoe, V. W. V., et al. (2014). Detecting bullying in early elementary school with a computerized peer-nomination instrument. Psychological Assessment, 26, 628-641.
Wieringa, R. (2009). Design science as nested problem solving. In 4th International Conference on Design Science Research in Information Systems and Technology. Malvern, USA.

Williford, A., Elledge, L. C., Boulton, A. J., DePaolis, K. J., Little, T. D., \& Salmivalli, C. (2013). Effects of the KiVa antibullying program on cyberbullying and cybervictimization frequency among Finnish youth. Journal of Clinical Child and Adolescent Psychology, 42, 820-833. https://doi.org/10.1080/15374416.2013.787623.

Wölfer, R., \& Scheithauer, H. (2014). Social influence and bullying behavior: intervention-based network dynamics of the fairplayer. Manual bullying prevention program. Aggressive Behavior, 40, 309-319. https://doi.org/10.1002/ab.21524.

Yeager, D. S., Trzesniewski, K. H., \& Dweck, C. S. (2013). An implicit theories of personality intervention reduces adolescent aggression in response to victimization and exclusion. Child Development, 84 , 970-988. https://doi.org/10.1111/cdev.12003.

Yeager, D. S., Fong, C. J., Lee, H. Y., \& Espelage, D. L. (2015). Declines in efficacy of anti-bullying programs among older adolescents: theory and a three-level meta-analysis. Journal of Applied Developmental Psychology, 37, 36-51. https://doi.org/10.1016/j. appdev.2014.11.005.

You, S., Furlong, M. J., Felix, E., Sharkey, J. D., Tanigawa, D., \& Green, J. G. (2008). Relations among school connectedness, hope, life satisfaction, and bully victimization. Psychology in the Schools, 45, 446-460. https://doi.org/10.1002/pits.

Young, S. (1998). The support group approach to bullying in schools. Educational Psychology in Practice, 14, 32-39. https://doi.org/10. 1080/0266736980140106. 